\title{
A CASE
}

OF

\section{SECONDARY TREPHINING}

Fo $\mathbf{R}$

\section{TRAUMATIC ABSCESS OF THE BRAIN.}

\author{
RECOVERY.
}

BY

JOHN WHITAKER HULKE, F.R.S., SURGKON TO THE MIDDLESEX HOSPITAI.

(Received February 11th-Read March 11th, 1879.)

The bearing of this case on the diagnosis of traumatic abscess in the brain, and on secondary trephining, has appeared to me to impart to it sufficient interest to justify me in bringing it under the notice of the Royal Medical and Chirurgical Society.

An errand boy, æt. 15, hurrying out of a factory at the ringing of the dinner-bell, pushed by a shop-mate, stumbled against an iron fence, by which his forehead was grazed nearly in the middle line, a little below the hair.

Stunned for a few moments he soon regained his senses, and walked to the Middlesex Hospital to have the graze dressed. It was deep, but it did not lay bare the bone, 
After this he went back to the factory and stayed there till evening, when, as he still felt shaken by the accident, a companion took him home.

He continued at his employment during the next month, but throughout this time he had more or less constant pain in the forehead, and he sometimes felt so ill that his master would dismiss him early in the day before the factory closed.

The graze festered, and it healed slowly. A month after the date of the injury he began to be troubled with nausea, and soon after to occasionally vomit without, he said, having done anything to provoke this.

One week later (five weeks after the injury), on 27th September, 1875, he was admitted into Percy Ward, Middlesex Hospital, under the care of Mr. Andrew Clark, who had charge of my beds during my vacation. His symptoms being considered indicative of intracranial inflammation leeches were put on the forehead and his head was kept cool with ice.

On October 10th, when he came under my care, he was lying on his back, his eyes shut; he seldom, I was told, moved, and he took little notice of what was occurring in the ward around him. When questioned he always complained of pain in the forehead, where the situation of the graze was marked by a small scar, tender, and tied to the underlying bone. His tongue was furred, slightly brown, and dry. He disliked eating, and he often retched. His skin felt dry and rough, but it was cool. Next day at noon I found him lying on his left side, and then first detected incomplete hemiplegia of this side. He could not grasp as strongly with the left hand as with the right, and the strength of his left thigh, roughly measured by holding it down on the bed whilst he tried to flex it, was plainly less than that of his right thigh. ${ }^{1}$ His pulse was only 48 per minute, and the temperature in the armpit was $97 \cdot 8^{\circ} \mathrm{F}$.

Believing an abscess to have formed in the right frontal

1 My colleague, the late C. De Morgan, confirmed the existence of the hemiplegia. 
lobe of the brain, I decided to trephine at the scar of the graze and make an outlet for the pus.

Chloroform was given, for although somewhat heavy in manner the boy was perfectly conscious.

When the coverings, including periosteum, were turned back, preparatory to setting on the trephine, a small starred crack in the outer table of the frontal bone became apparent. It occasioned no unevenness of the outer surface, and it did not penetrate to the inner table. A disc of bone $\frac{7}{16}$ inch diameter was cut out. About $\frac{\mathrm{I}}{3}$ (the left) of its inner surface was rough. This was evidently merely the mark of the more intimate adhesion of the dura mater bounding the superior longitudinal sinus which was exposed at the extreme left of the bore-hole. At the right of this the dura mater bulged up tensely into the bore-hole, but its outer surface appeared healthy, and there was not anything observable which might denote abscess beneath it in the subdural space or under the (visceral) arachnoid. The cerebral pulsation was apparent. In the expectation that the pus was more deeply piaced, a fine trocar, connected with a partly exhausted aspirator, was now pushed through the membranes into the brain at the right of the bore-hole, and when it had reached a depth of about one inch, thin greenish pus rose into the syringe. The rough characters of the fluid were unmistakable, and they were afterwards confirmed by microscopic examination. A free opening into the abscess was next made with a narrow knife passed upon the trocar as along a guide, and through this opening, and also through the trocar, a quantity of pus, estimated at between ऊiij and ziv escaped. While enlarging the opening, although care was taken to keep the edge of the knife as far as possible from the situation of the longitudinal sinus, a minute slit was made in its extreme border from which a fine stream of blood spurted to a distance of about one foot. Slight pressure with the finger tip stopped its flow, but the paramount necessity of leaving the bore-hole quite free for the drainage of the abscess forbade the use of a compress. The lips of this little slit were, therefore, transfixed with a very 
fine suture, in passing which care was taken to avoid including the lining, the stitch was knotted and then a thread was tied circularly round, the slit being kept from slipping by the knot which acted as a button. This little mancuvre is mentioned only as a hint to others who may meet with a similar difficulty. I had several years before found it efficient in the arrest of bleeding from a small vein dipided close to its termination in the axillary trunk. During the operation and subsequently antiseptic precautions were strictly observed.

The immediate effects of the operation were the disappearance of the hemiplegia and the cessation of the retching. The pain in the forehead subsided slowly. During the first fortnight the pulse rate ranged between 48 and 55, and the temperature was generally below the normal average. There was a slight escape of pus from beneath the skin-flap which had been loosely replaced over the bore-hole, but this ceased after a few days, and before the end of October the wound had closed.

Notwithstanding this local progress the boy's general condition for a long time was unsatisfactory. Although his appetite returned, so that he ate with relish a muttonchop for dinner, yet he lost flesh. He himself invariably told me that he felt better.

November 7th, nearly one month after the operation, the ward-sister noticed that he seemed to grope upon his plate for his food as if he did not plainly see it. I now found that the visual acuteness of both eyes was blunted and detected in both the characteristic signs of neuro-retinitis. For this mercury was rubbed in until the gums were slightly touched, and its influence was gently maintained for one month. Under this treatment the sight of the right eye improved so much that he became able with it to read small print and see the hands of a watch at the distance of one foot; but the improvement did not continue, and eventually both optic papillæ underwent atrophy, and both eyes became blind.

At the end of December he left the hospital in fair general health. About six months later he was brought again on 
account of fits. They were probably epileptic. Potassic bromide was prescribed with relief. I saw him last summer, he had become stout and looked hearty. He had not had a fit for a long time. He was then under instruction in an industrial school, and I was told that he was an intelligent, well-conducted pupil.

In injuries of the skull affecting its contents, greatly as surgeons have differed respecting other indications for trephining, all, I believe, have ever agreed that it is proper to trephine where this is necessary to afford escape to the contents of an abscess in the brain. In the application of this precept uncertainty of diagnosis constitutes a real diffculty which has injuriously limited its practice. The question whether an intra-cranial abscess can be inferred with so high a degree of probability as to justify so grave a proceeding as trephining has been differently answered by surgeons of great experience.

Not to refer to writings of past times, in our own day we find one eminent authority formulating groups of symptoms by the aid of which not merely may suppuration inside the skull be recognised, but the diffused distinguished from the localised, and the depth of the abscess gauged, whether in diploë, between inner table and dura mater, in subdural space, under the (visceral) arachnoid, or, lastly, in brain. Another equally eminent authority diffidently acknowledges his inability to lay down clinical characters by which the diffuse can be discriminated from localised suppurations within the skull, and the seat of the latter inferred with more than relatively slight probability.

In the case just narrated hemiplegia was the symptom which decided me to trephine in the belief of the presence of abscess in brain. I am aware that a very distinguished clinicist has expressed the opinion that hemiplegia (when separated by so great an interval of time from the date of injury that it cannot be properly regarded as the immediate and direct result of brain-lesion) is symptomatic of arachnitis; but I submit that when hemiplegia supervenes after such an interval of time it is significant of a morbid process 
proceeding in the brain itself rather than in its membranes, and when inflammation of these occurs it is secondary and of subordinate importance. The following case, which I had an opportunity of watching when attached to the General Hospital in the front before Sebastopol, early impressed me with this.

A private in a line regiment was struck by a glancing rifle-bullet on the vertex just to the right of the middle line. The scalp was scored, but the bone was thought to have escaped injury. The eschar fell, the wound granulated and had nearly healed, leaving, however, a small sinus. Throughout this time there were not any brain symptoms. He then complained of not feeling well, his indisposition increased; violent pain in the crown of the head set in; he began to retch; and next day his left arm was palsied. Bare bone being now felt on probing the sinus it was decided to trephine. When the scalp had been turned back the upper and posterior angle of the right parietal bone was found splintered and depressed. Some loose splinters were removed and the depressed bone raised. The exposed dura mater had not been torn, and it did not exhibit any indication of disease. Nothing further was done. The symptoms continued unrelieved; delirium and great fever shortly followed and death took place on the second day after the trephining.

At the necropsy, on examining the head an abscess was found in the right cerebral hemisphere directly beneath the fracture, close to the surface of the brain. From this spot, as from a focus of infection, the web of the pia mater was infiltrated to a considerable distance with a greenish seropurulent fluid. It was a matter of regret that, on not finding pus between the bone and dura mater, the surgeon had not cut through this into the brain; in the patient's desperate state it would have added little to his danger, and it might have afforded him a chance of surviving. The rather sudden and great accession of fever after the operation marked, it was thought, the onset of the purulent meningitis which might have been averted by the timely evacuation of the abscess. 